\title{
The Permeability of Cigarette Papers and Cigarette Ventilation*
}

\author{
by William A. Selke and Jobn H. Matbews \\ Research Department, Schweitzer Division, Kimberly-Clark Corporation, \\ Lee, Massachusetts, U.S.A.
}

\section{INTRODUCTION}

The growing emphasis on the gas phase of cigarettes gives new interest to the prediction of the dilution of cigarettes, whether through the paper wrapping the tobacco rod or through a ventilating filter. Calculation of these dilution flows requires knowledge of the relationship of pressure drop and air flow through the various types of paper used in the construction of cigarettes.

In 1966 Lipp (1) published an important paper showing that the flow of air through some types of paper was not directly proportional to the pressure difference across the paper, and proposed a modification of his earlier method of measurement of permeability (2) based on these findings. This general principle of measurement of air velocity through paper at fixed and known pressure differentials has been incorporated in the Coresta Recommended Method No. 3 (3). By contrast, in earlier measurement techniques the pressure drop is either not constant or standard, e. g. the Greiner method, or is at a level far in excess of that occurring during the smoking of a cigarette. It is the extension of this improved technique and the interpretation and application of the results with which this present paper deals.

\section{General Permeability Equation}

Since, in general, air flow through paper is not linearly related to pressure drop, at least two constants are required to characterize any paper. A simple and most convenient form is that of Equation 1:

$$
\mathrm{V}=\mathrm{k}(\Delta \mathrm{P})^{\mathrm{n}},
$$

when

$\mathrm{V}=$ velocity of air through the paper $(\mathrm{cm} / \mathrm{min})$,

$\Delta \mathrm{P}=$ pressure differential across the paper $\left(\mathrm{cm} \mathrm{H}_{2} \mathrm{O}\right)$, $\mathrm{k}, \mathrm{n}=$ constants, characteristic of the particular paper.

This form is clearly appropriate for two limiting cases. For flow through packed beds or fine capillaries, $n$ is unity, and the exponential form is unnecessary. For sharp-edged orifices where increase in kinetic energy, rather than friction, constitutes the principal limit to flow, $\mathrm{n}$ is close to one-half for cases in which the pressure

* Presented, in part, at the Coresta Technology Study Group meeting held in Munich, Germany, in September 1977. drop is relatively small (4). However, it must be determined whether the model represented by this equation has more general applicability.

The plotting and interpretation of data are facilitated by the employment of functions which are linearly related. For the model represented by Equation 1, the use of $\log$ scales for both coordinates of a graph results in straight lines, the slope being the exponent, n. In Fig. 1 are plotted the lines representing the two limiting cases together with an intermediate case, $n=0.7$, which had been suggested as representing perforated paper in an earlier publication (5). It should be noted that all three papers represented by these lines would be reported as having the same Coresta permeability, measured at $10 \mathrm{~cm} \mathrm{H}_{2} \mathrm{O}$ W.G.

Air flow through paper is through pores, large and small, straight or circuitous, and through holes, inadvertent or produced by perforation with any of several techniques. Pores are generally present in paper, whether or not there are also larger flow channels. Thus, in the general case, air flow takes place simultaneously through one or more types of channels in parallel.

Figure 1. Log plot of models having different values of $n$ in Equation 1, all having same nominal Coresta permeablilty.

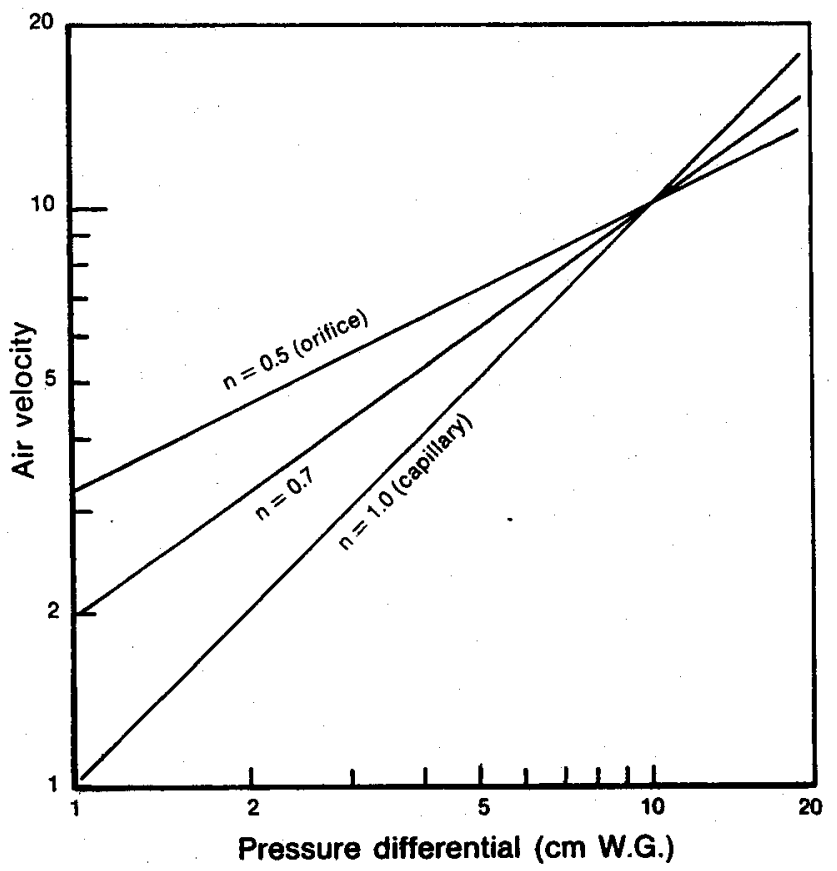


Flgure 2. Flow characteriatice of model with parallel flow through channels represented by values of the exponent $n$ of 1.0 and 0.5 .

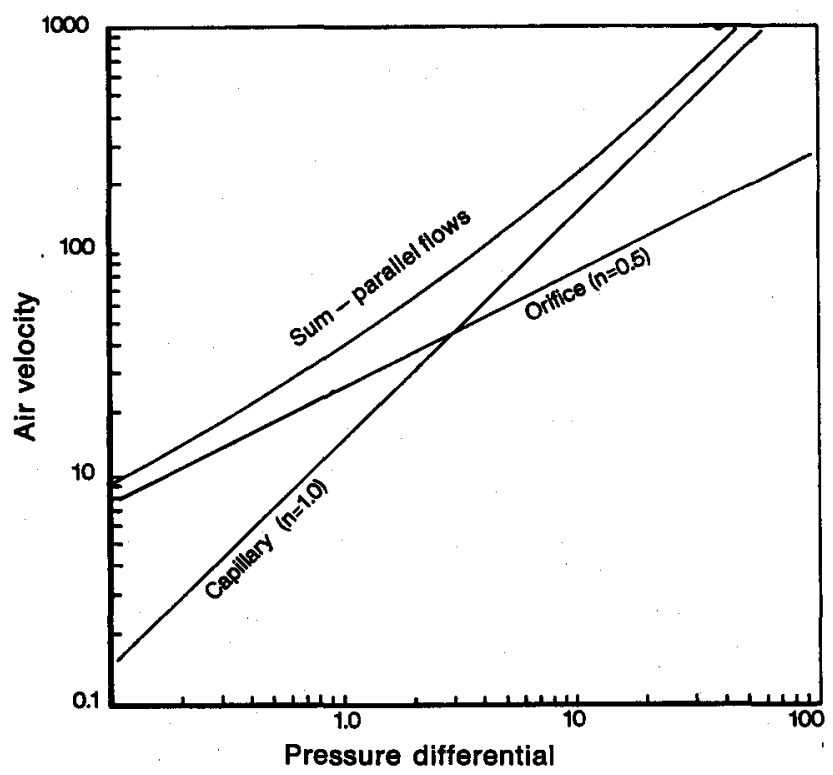

The log plot, Fig. 2, represents a model with parallel flow through pores and sharp-edged orifices, with the portion of the flow through each shown separately, as well as the sum of these flows. It should be noted that at high values of pressure differential the flow is predominantly through the pores, while at low differential it is predominantly through the orifices. The line representing the sum of these two flows is not straight, asymptotically approaching the curve $\mathbf{n}=1.0$ at high pressure drop and $n=0.5$ at low pressure drop. There is noticeable curvature, in the region where the two flows are nearly equal. Because of the curvature of this line, Equation 1 is not a general representation of this model. Thus it remained to be determined whether Equation 1 is adequate to represent papers of interest in cigarette construction, which might derive part of their permeability through perforation, in parallel to some natural porosity.

\section{EXPERIMENTAL}

\section{Permeability Measurements}

The measurements of air permeability referred to later in the paper were all made using equipment conforming to the Coresta standard. The air flow rates were measured with a rotameter. Since some papers of extremely high permeability were tested, care was taken that the outlet of the paper-holding clamp did not offer significant resistance at the high flow rates encountered. This was checked by passing air through the equipment with paper absent, and noting that the reading of pressure drop was negligible. In each measurement of permeability, readings of air flow were taken at various pressure differences from $10 \mathrm{~cm} \mathrm{H}_{2} \mathrm{O}$ (approximately 1.0 centibar) to $1.0 \mathrm{~cm} \mathrm{H}_{2} \mathrm{O}$.
Flgure 3. Log flow plots of clgarette paper before $(x)$ and after $(O)$ perforation together with line for orifice flow equal to contribution of the perforation and sum of that orifice and the original paper.

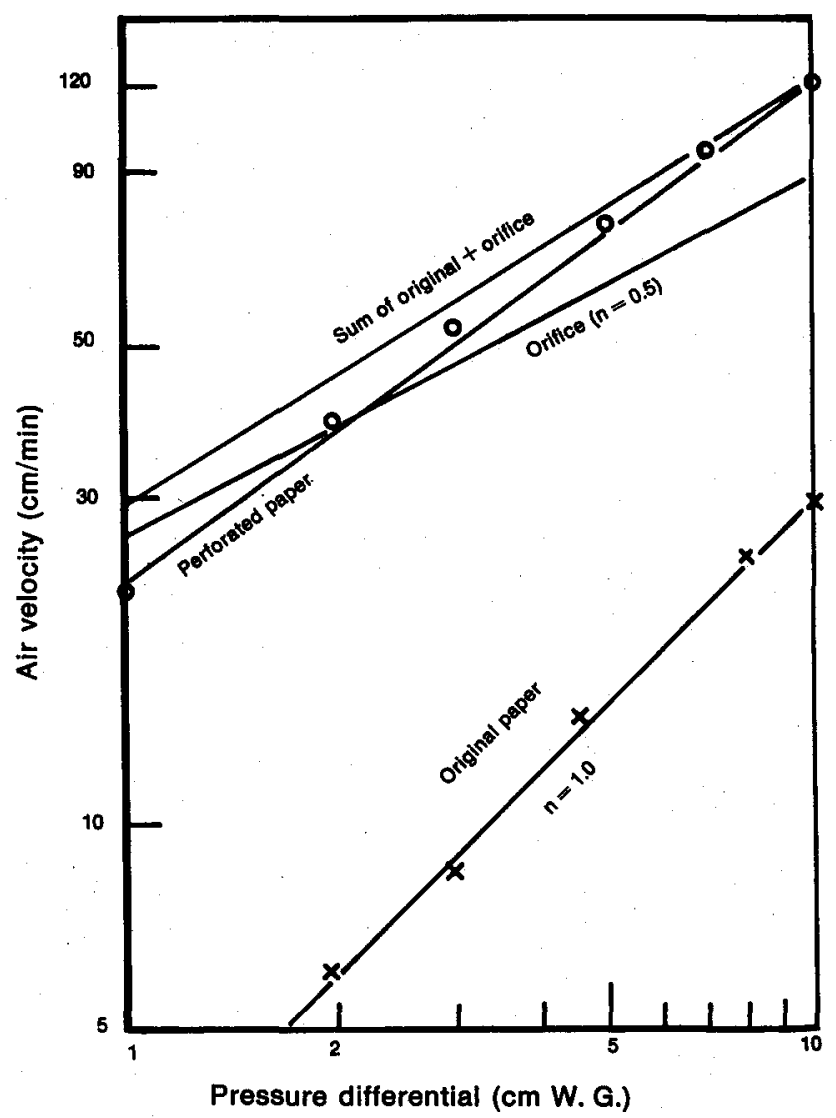

\section{Perforated Cigarette Paper}

In the light of what is seen in Fig. 2, we looked at electrically perforated cigarette paper. Since the perforating process is somewhat influenced by the paper being perforated, valid conclusions could not be drawn from perforations made in non-permeable paper, so the role of the perforations had to be separated by treatment of the data.

In Fig. 3, data on a cigarette paper with a permeability of $30 \mathrm{~cm} / \mathrm{min}$ (at $10 \mathrm{~cm} \mathrm{H}_{2} \mathrm{O}$ ) are plotted, as are measurements on the same paper after the permeability was increased to 120 of the same units by perforation. Both sets of data are well fitted by straight lines, with slopes of 1.0 and 0.72 respectively. The permeability added was thus 90 units, at $10 \mathrm{~cm} \mathrm{H}$ O. If this additional permeability, the perforations, were in the form of sharp-edged orifices, flow through it would be represented by the line labeled $n=0.5$. The sum of the flow represented by that curve for the orifices and that through the original pores is the uppermost line. This derived line, unlike the actual data, is not straight as would be expected from Fig. 2, and clearly deviates from the data at low pressure differentials.

In Fig. 4, a line is shown representing the result of subtracting the flow through the porosity of the original paper from that measured through the perforated paper at the same values of pressure drop. The resulting curve, 
Figure 4. Log plot of flow through cigarette paper before $(x)$ and after $(O)$ perforation and difference, representing the flow through the perforation.

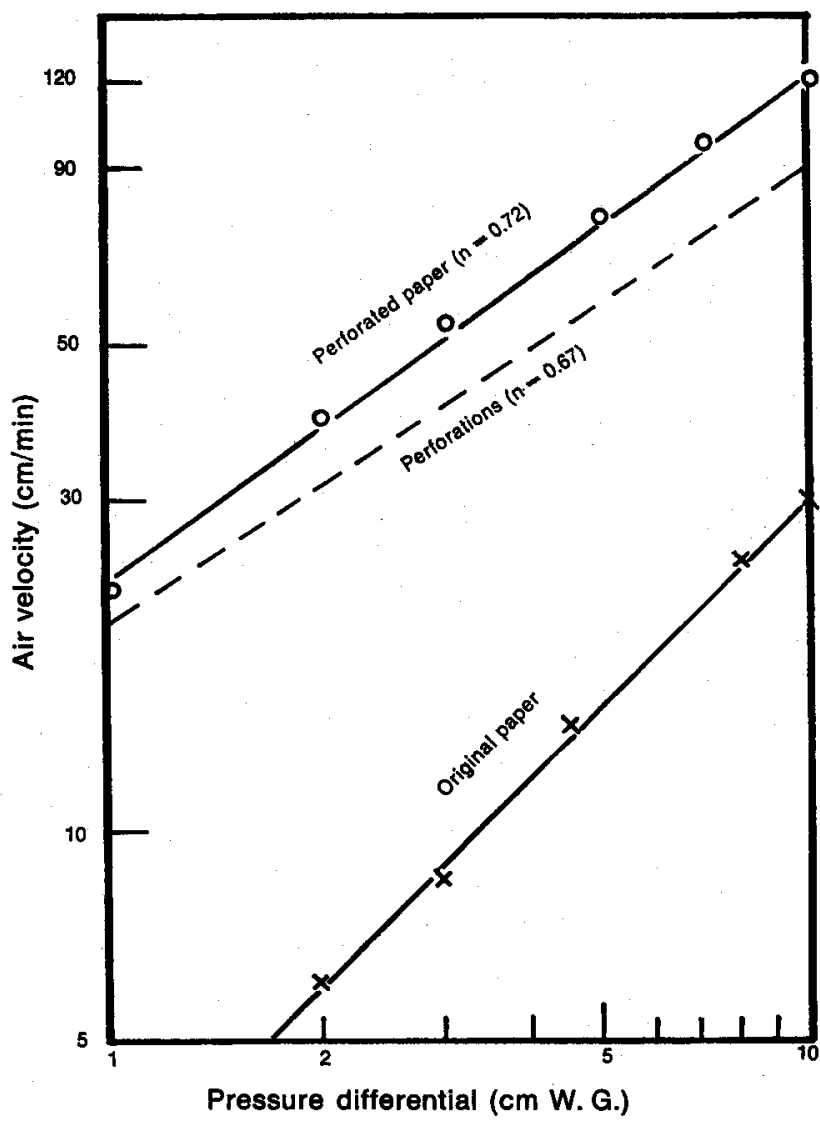

representing the actual flow through the perforation, is straight but is not fitted by an exponent of 0.5 , but instead by $n=0.67$. The small perforations are thus not represented by the model of the sharp-edged orifice.

The log plot representing the actual perforated paper, unlike the model in Fig. 2, is adequately represented by Equation 1, since the line is straight, and thus $n$ is constant. This fortunate circumstance reflects [1] the fact that the flows through the parallel channels are not equal (the point of maximum curvature) in the range of measurement, aided by, [2] the slope of the lines representing the two parallel flow paths are not different by

Table 1. Flow exponents in Equation 1 of varlous papers.

\begin{tabular}{lr|l} 
& Permeability & $\mathrm{n}$ \\
\cline { 2 - 3 } & & \\
\hline $\begin{array}{l}\text { Cigarette paper } \\
\text { porous }\end{array}$ & 45 & 1.0 \\
$\quad$ electrically perforated & 120 & 0.72 \\
electrically perforated & 200 & 0.70 \\
Plug wrap & & \\
$\quad$ porous & & \\
$\quad$ porous & 1,800 & 0.73 \\
$\quad$ electrically perforated & 30,000 & 0.69 \\
$\quad$ & 240 & 0.59 \\
Tipping & & \\
$\quad$ laser perforated & & 0.52 \\
$\quad$ electrically perforated & & 0.68 \\
\hline
\end{tabular}

Figure 5. Alr velocity through samples of porous plug wrap paper as a function of pressure differential.

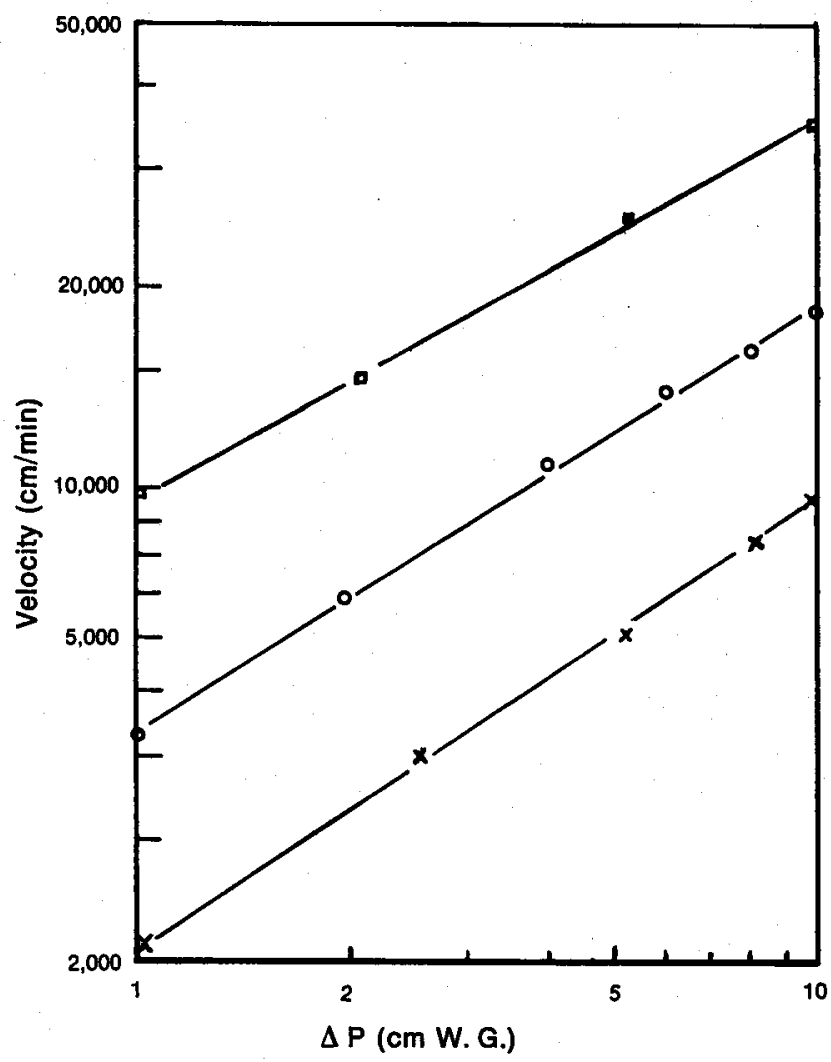

a full 0.5 . In papers of technical interest one or both of these factors lead to the flow characteristics giving an essentially straight $\log$ plot and Equation 1 being a satisfactory description.

\section{Porous Plug Wrap Papers}

While measurements of cigarette paper with even high degrees of natural porosity exhibit very close to a linear relationship between flow velocity and pressure differential $(n=1.0)$, very permeable plug wrap papers, as are used in ventilating filters, show quite different flow characteristics. Fig. 5 shows more typical data on three different samples of porous plug wrap papers. The data are well fitted by straight lines, so Equation 1 can serve to represent these papers, also.

Table 1 shows values of the exponent, $n$, determined on a number of types of porous plug wrap paper. Since that exponent is not only not unity, but differs for the various papers, measurements at more than one pressure differential are essential to characterize the paper.

\section{Effect of Flow Exponent Less Than Unity}

The lower the exponent in Equation 1, the less the dependence of air flow on the pressure differential. To judge the importance of that phenomenon, we have investigated the pressure levels within a range of types of cigarettes. The aim was to determine how those levels might differ from the measuring value of $10 \mathrm{~cm} \mathrm{W.G.}$ This was done by compurer, using an incremental technique. 
It has been shown $(6,7)$ that a lit coal adds a significant resistance to draw to an unlit tobacco column. For this reason, empirical data were obtained relating the pressure drop of the coal, itself, to the air flow through it as well as of the resistance to draw of the tobacco column, overwrapped to prevent air influx, also as a function of air flow.

In the computation, the cigarette was regarded as divided into short elements of length. The flow leaving each element is calculated by adding the dilution flow created by the vacuum level in that element to the flow entering from the element upstream, that dilution flow being calculated by Equation 1 .

First, a value for the flow through the coal is assumed and the proper value of coal pressure drop taken from the empirical data. The computation is continued, stepwise, until the element is reached for which the exit flow is the standard value of $17.5 \mathrm{ml} / \mathrm{s}$. The length of cigarette required for the dilution to bring the assumed flow through the coal up to that standard value is thus indicated. This whole procedure is repeated for different assumed values of flow through the coal. By trial and error, the dilution flow and pressure distribution with a given paper wrapper can be determined for any rod length. The exponential form of Equation 1 was convenient for this calculation.

One example (8) demonstrates the difference in performance between naturally porous and perforated paper. Fig. 6 shows the pressure distribution within tobacco rods during the second puff on $85 \mathrm{ml}$ cigarettes with $25 \mathrm{~mm}$ tipping paper. Two cigarettes are represented, one wrapped with porous paper $(n=1.0)$ and one with electrically perforated paper $(n=0.72)$, both papers having a permeability of $50 \mathrm{~cm} / \mathrm{min}$ (at $10 \mathrm{~cm} \mathrm{H} \mathrm{H}_{2} \mathrm{O}$ ). Two things should be noted. First, that the vacuum level along the entire length of the cigarettes is less than $10 \mathrm{~cm} \mathrm{H}_{2} \mathrm{O}$, and, second, that as a consequence of the low pressure differential across the paper the dilution through the perforated paper is greater than that through the porous paper, the values being $39 \%$ and $33 \%$,

Figure 6. Pressure dlatribution during firet puff along clgarettes wrapped with naturally porous papers and electrically perforated papers of the same nominal permeablilty.

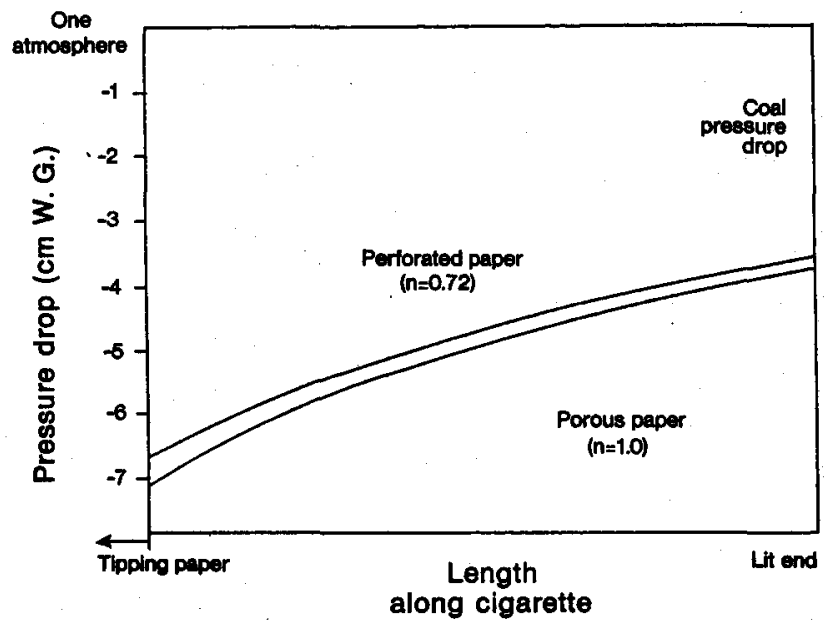

respectively. This is consistent with the findings of Lipp and van Nooy (2).

They had proposed to deal with this flow phenomenon by taking the readings of the permeability of perforated papers at $2.5 \mathrm{~cm}$ W.G. rather than at $10 \mathrm{~cm}$ W.G. While that approach was an important advance, determination of the terms $k$ and $n$ in Equation 1 is more general and rigorous.

Since porous and perforated papers perform differently at the same nominal permeability, it was of interest to determine the comparative values of permeability of porous and perforated paper to provide similar dilution during an early puff. Two examples are as follows:

Table 2. Permeablitties to provlde slmilar dilution - firet puff (85 mm cigarettes, $25 \mathrm{~mm}$ tipping paper).

\begin{tabular}{l|l|c}
\hline & $\begin{array}{c}\text { Porous paper } \\
(n=1.0)\end{array}$ & $\begin{array}{c}\text { Perforated paper } \\
(n=0.72)\end{array}$ \\
\hline
\end{tabular}

Permeability

45
38

240

173

The vacuum level within cigarettes wrapped with highly permeable paper increases with puff number, so the difference in characteristics between porous and perforated papers diminish as the cigarette is smoked. On the other hand, the absolute amount of dilution diminishes to a negligible level as the coal approaches the tipping paper. For identical dilution, integrated over the length of the cigarette, the differences in permeabilities required for the two types of paper are thus only slightly less than for the first puff.

While it is outside the scope of this paper, it should be mentioned that differences in dilution of cigarettes made with permeable papers play a smaller role in dictating the smoke delivery than differences in the smolder rate of the cigarettes. The smolder rate is influenced by the natural porosity of the paper, but is further controlled by chemical additives.

\section{Vacuum Level in Cigarettes}

In another approach to this same subject, the pressure differential across the paper of cigarettes was investigated by experimental measurements and by application of the computer program mentioned above. The measurements were of the vacuum level of $85 \mathrm{~mm}$ filter cigarettes, made with a wide range of papers, with the filters removed, the values calculated back to the beginning of the tipping paper. The experimental points and the lines representing the computed values appear in Fig. 7.

This plot is of interest relative to ventilating filters. The vacuum level at the tipping paper differs from that at the vents by the pressure drop through part of the filter, but the change in vacuum level as the cigarette is consumed and resulting change in dilution flow into the vents of the filter is indicated qualitatively.

Because of the pressure drop along the rod, the pressure differential across the cigarette paper is lower along the 
Figure 7. Experimental points and computed values of vacuum at tipping papers of clgarettes wrapped with paper of different permeabilitles.

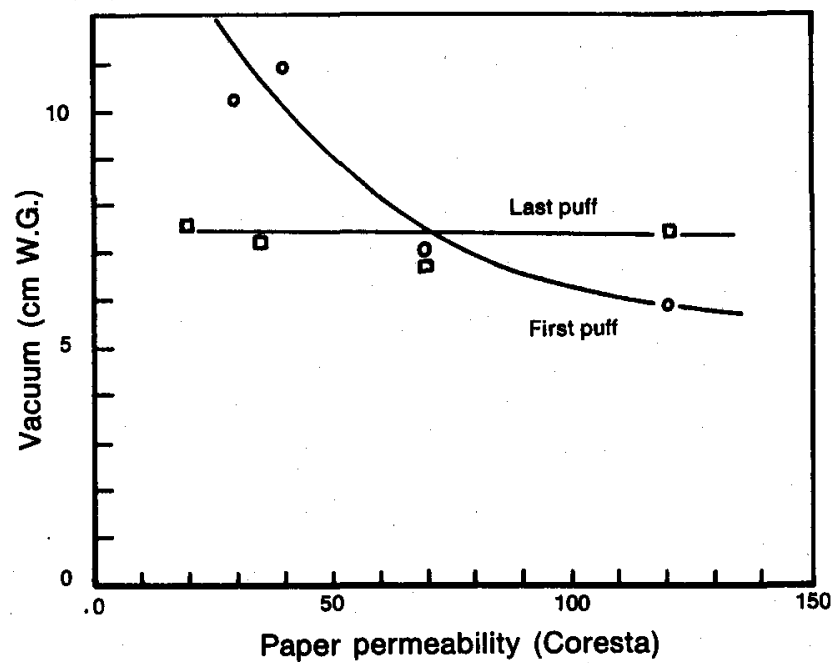

length of the cigarette than at the beginning of the tipping paper, but it approaches that value during the last puff.

The mean differential, defined as that value of $\Delta P$ in Equation 1 which, calculating from the area of paper on the cigarette, would cause the dilution measured for the cigarette, was calculated for the cases in Fig. 7. These values are plotted as Fig. 8. It shows that for cigarettes made with permeable wrappers, the mean vacuum levels are much lower than $10 \mathrm{~cm} \mathrm{W.G.} \mathrm{The} \mathrm{use} \mathrm{of} \mathrm{ventilating}$ filters will, of course, further reduce the vacuum level within the cigarette.

Figure 8. Mean vacuum level during first and last puffs for clgarettes as a function of the permeability of the wrapper.

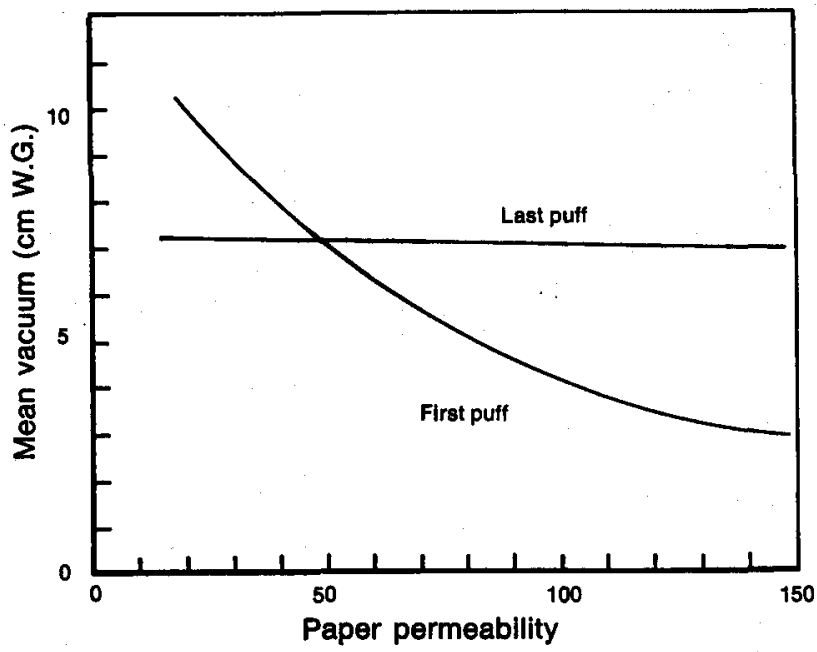

\section{Application to Ventilating Filters}

With the increasing use of ventilated filters, it was of interest to determine to what extent the resistance to air flow into the vents of these filters could be predicted by measurements on the papers comprising these filters. It was apparent at the outset that differences in assembly could influence the overall flow resistance, so the need
Figure 9. Cross section of ventilated filter.

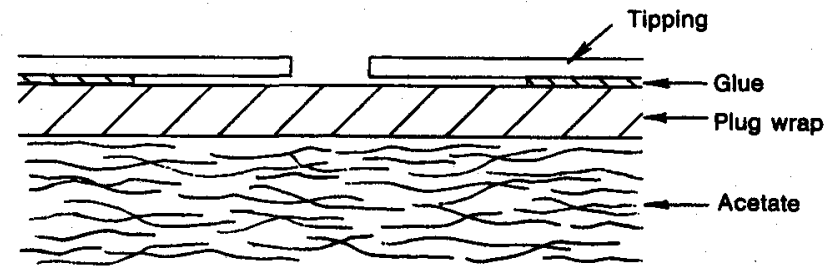

for empirical measurement was unavoidable. But with a suitable model for calculation, the number of such measurements required can be kept at a minimum.

Fig. 9 shows a cross-section of a typical construction at the point of a perforation in the tipping paper. The air entering the perforations passes through the porous plug wrap paper and then flows at least partially into the body of the filter. The drawing shows an appreciable space between the tipping paper and the plug wrap paper throughout the area generally left unglued. However, in reality these layers are pressed together to some degree, impeding lateral flow. Thus, the area of plug wrap paper through which the air passes is less than the total area left unglued, although greater than the area of the perforations in the tipping paper. If this effective area of plug wrap paper is determined by empirical measurement, the air flow resistance of the vent can be calculated. For example, the effect on the overall resistance of changing the permeability of the plug wrap paper can be predicted once one knows what area of that paper conducts air.

In addition to the flow resistance offered by the tipping paper and the plug wrap there is the potential of a resistance in the interface of the plug wrap and the filter medium. Fortunately, this can be neglected.

\section{Experimental Determination of Overall Resistance}

Since the flow resistance depends on the assembly, measurements must be made on finished tips. Two measurements were made, one of the flow into the vents and out the end of the filter, the other a measurement of the resistance to draw of the filter. These measurements are defined in Fig. 10.

Tests were made on two commercial cigarettes. Cigarette A had two rows of laser perforation in the tipping and cigarette B had four rows of extremely fine holes, also made by laser.

Figure 10. Scheme of two measurements and calculation to obtain values of net of pressure drop through vents ( $\Delta$ P $_{\text {NET }}$ ).

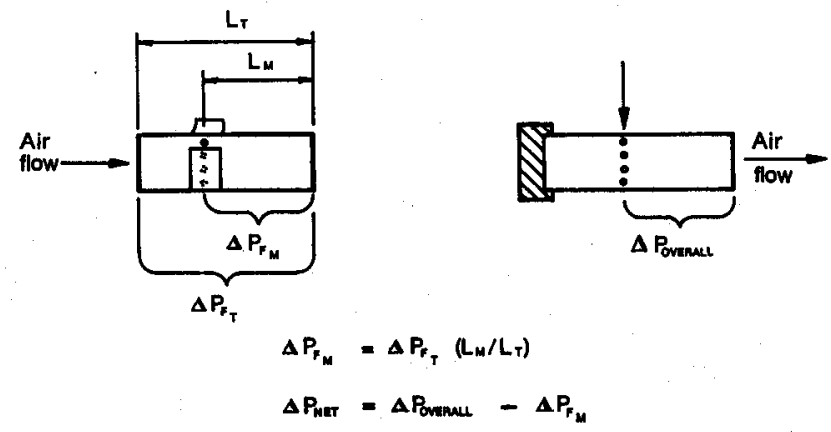


Figure 11. Pressure drop values from clgarette A (measurements as in Figure 10).

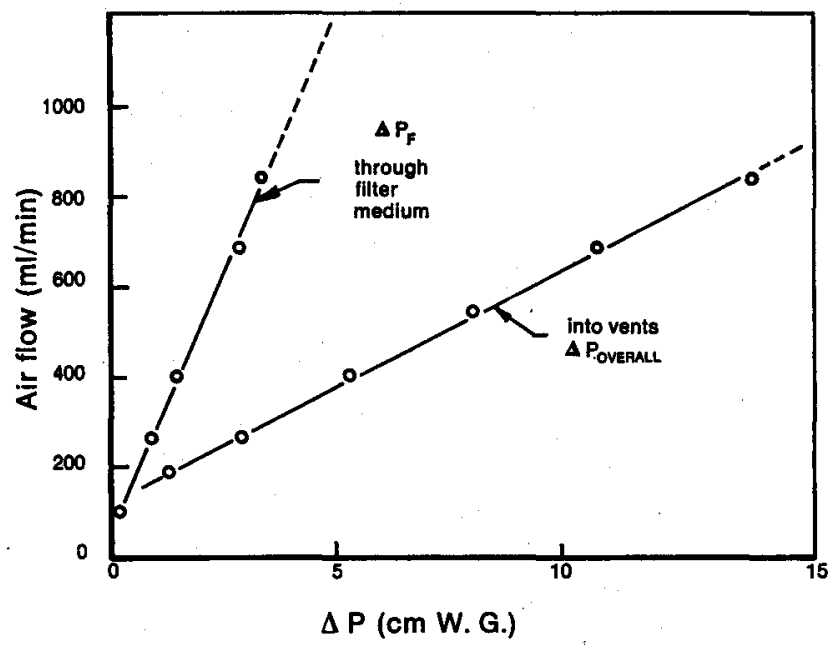

The filter tips were first removed from the cigarettes. For the first measurement, the end of the tip which was toward the tobacco rod was sealed with wax. The tip was inserted in the rubber dam of a Cambridge filter holder, vacuum applied, and the air flow measured as a function at successively higher levels of vacuum. The readings were completed when either the vacuum level reached $14 \mathrm{~cm} \mathrm{W.G.} \mathrm{or} \mathrm{the} \mathrm{air} \mathrm{flow} \mathrm{reached} 900 \mathrm{ml}$ per minute. The resistance to draw was measured on another filter, this time covering the vents in the filter with pressure-sensitive tape. When two-part filters were tested in which the vents entered the cellulose acetate portion toward the mouth, the filter was cut at the junction of the two filter media, and measurements made on only the cellulose acetate section.

Measurements made on cigarette A are shown in Fig. 11. The net pressure drop of the ventilation, itself, was calculated by subtracting the pressure drop of that length of filter included in the measurement from the overall value. This amount to be subtracted was calculated as that fraction of the total pressure drop of the filter proportional to the length from the center of the perforations to the mouth end of the filter. The values of this net ventilation resistance are plotted as Fig. 12.

Since we did not know the characteristics of the different papers of which these filter tips were constructed,
Figure 12. Net pressure drop of vents of cigarette A.

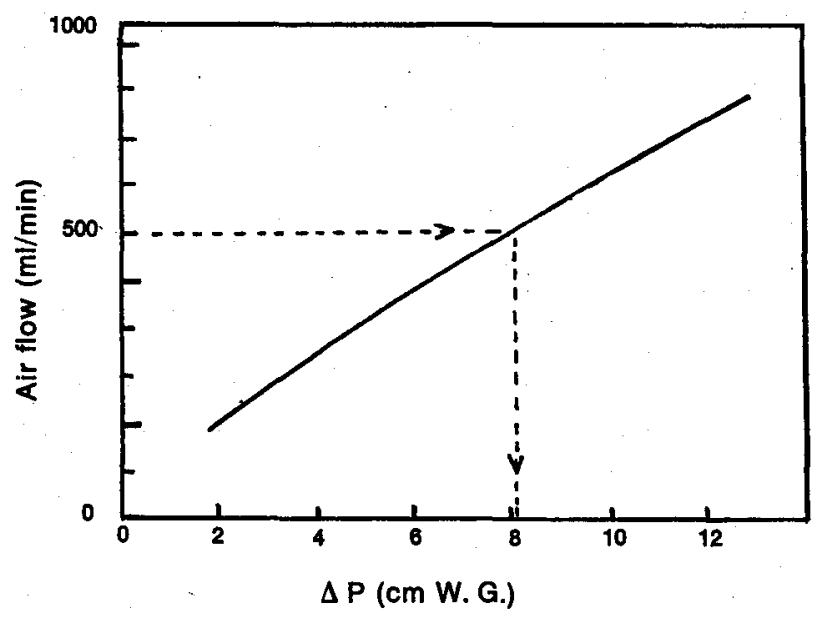

a filter was carefully dissected to obtain small samples of the tipping paper and porous plug wrap paper. These were taped onto holders for determination of their permeabilities.

The permeability of the tipping paper was expressed in terms of volume flow per millimeter of cigarette circumference as a function of pressure drop. It was plotted on $\log$ coordinates and the results expressed in terms of constant and exponent. It should be noted that for large perforations, this curve can be approximated from the equation for orifice flow (4). This is essentially Equation 1, with $\mathrm{n}=0.5$ and the value of $\mathrm{k}$ calculated from the open area with appropriate conversion of units.

From these data, the effective area of the porous plug wrap was calculated by the following procedure.

\section{Calculation of Effective Area}

1. Choose an arbitrary value of dilution flow, in the range of that occurring during smoking. This value was

$600 \mathrm{ml}$ per minute for cigarette $A$ and $300 \mathrm{ml}$ per minute for cigarette $B$.

2. Read the value of $\Delta P_{\text {NET }}$ across the assembled ventilation system from a plot similar to Fig. 12.

3. Calculate $\Delta P_{T}$ across the tipping for that flow.

4. Subtract $\Delta P_{T}$ from the value of $\Delta P_{\text {NET }}$ to obtain value of $\Delta P_{P}$ across plug wrap.

Table 3. Calculation of effective area.

\begin{tabular}{|c|c|c|c|c|c|c|c|}
\hline \multirow[b]{2}{*}{ Cigarette } & \multirow[b]{2}{*}{$\begin{array}{l}\text { Arbitrary } \\
\text { dilution } \\
\text { flow }\end{array}$} & \multirow[b]{2}{*}{$\begin{array}{l}\text { Overall } \\
\Delta \mathrm{P}_{\mathrm{V}} \\
\text { (cm W.G.) }\end{array}$} & \multirow[b]{2}{*}{$\begin{array}{l}\text { Tipping } \\
\Delta \mathbf{P}_{\mathbf{T}}\end{array}$} & \multirow[b]{2}{*}{$\begin{array}{l}\text { Across } \\
\text { plug wrap } \\
\Delta P_{P}\end{array}$} & \multicolumn{3}{|c|}{ Perforation } \\
\hline & & & & & $\begin{array}{l}\text { Effective } \\
\text { area } \\
\left(\mathrm{cm}^{2}\right)\end{array}$ & $\begin{array}{l}\text { Actual } \\
\text { equivalent } \\
\text { diameter } \\
\text { (mm) }\end{array}$ & $\begin{array}{l}\text { Effective } \\
\text { diameter } \\
(\mathrm{mm})\end{array}$ \\
\hline A & 600 & 8.1 & 1.3 & 6.8 & $\begin{array}{c}0.037 \\
(20 \text { holes) }\end{array}$ & 0.29 & 0.49 \\
\hline $\mathbf{B}$ & 300 & 10.2 & 1.6 & 8.6 & $\begin{array}{c}0.061 \\
\text { (200 holes) }\end{array}$ & 0.084 & 0.19 \\
\hline
\end{tabular}


5. Calculate velocity of air flow through plug wrap resulting from that value of $\Delta P_{P}$, by Equation 1 or from plot similar to Fig. 5.

6. Divide total flow by velocity to obtain value of effective area.

7. Compare this effective area with the geometric area of perforations in the tipping.

The results of these determinations are given in Table 3 .

From the size and number of holes present it was calculated that the effective area was equivalent to unimpeded lateral flow around the perforations for a distance of $0.1 \mathrm{~mm}$ in the case of cigarette $A$ and $0.05 \mathrm{~mm}$ in the case of cigarette B. Values of the lateral flow width of this magnitude have been determined for a number of types of cigarettes. In some cases this width is increased with increasing pressure differential and increasing flow, apparently reflecting a spreading apart of the paper layers by the air pressure, but further work is necessary to quantify this. If this phenomenon is found to occur generally, it will be important to make determination at the levels of pressure drop occurring in that cigarette during smoking.

\section{Flow Controlling Pressure. Drop}

In both cigarettes $A$ and $B$ the pressure drop was predominantly across the porous plug wrap. Thus, the dilution flow would be affected by variation in the permeability of the porous plug wrap to almost as great a degree as by variation in the area of the perforation. If the resistance presented by the plug wrap were much less, variations in it would have a lesser influence on the total resistance.

Returning to cigarette $B$, and using the value for effective area determined above, we can see the effect of changing the permeability of the porous plug wrap paper. The plug wrap on cigarette $B$ had moderate permeability, 5400 measured by the Coresta system. This could be changed to paper of extremely high permeability, i.e. 26,000 units, and the number of perforations reduced so as to maintain the same nominal dilution. This is designated cigarette $B$ '.

The amount of perforation then required was calculated by trial and error using essentially the reverse of the steps listed above. This shows the number of holes can then be reduced from 200 to 85 and the pressure drops are then distributed as shown in Table 4. The redistribu-

Table 4. Cigarettes with equal dilution.

\begin{tabular}{|c|c|c|c|c|}
\hline & $\begin{array}{c}\text { Plug } \\
\text { wrap } \\
\text { permea- } \\
\text { bility }\end{array}$ & $\begin{array}{l}\text { No. of } \\
\text { holes }\end{array}$ & $\Delta P_{\text {tipping }}$ & $\Delta P_{\text {plug wrap }}$ \\
\hline Cigarette B & 5,400 & 200 & 1.6 & 8.6 \\
\hline Cigarette B' & 26,000 & 85 & 7.1 & 3.1 \\
\hline
\end{tabular}

tion of pressure drop between the tipping perforations and the plug wrap is accentuated by the nature of the flow through each. The values of the exponent $n$ in Equation 1 are different, viz. 0.55 for the tipping paper and 0.7 for the porous plug wrap papers. The pressure differential across the tipping increases more with increasing velocity than that across the plug wrap.

With cigarette $B$ ', the fraction of the overall pressure drop across the plug wrap is so small that minor variations in the permeability of the plug wrap paper have negligible effect on the dilution flow. Hence, cigarettes similar to $B^{\prime}$ are likely to be more uniform in performance than ones of type $B$, made with less permeable plug wrap.

Another ramification of the pressure redistribution should be noted, even though it is at most a second order influence. Expressing the overall series resistance in terms of Equation 1, we see that when more of the pressure differential is across the tipping paper, the exponent $\mathrm{n}$ is less than when it is across the plug wrap paper. Thus, the dilution flow changes somewhat less with changes in the imposed vacuum level. This can have an influence, however small, on the relative change in dilution as the cigarette is smoked. Whether this is favorable or unfavorable depends on the permeability of the cigarette paper, as is shown in Fig. 7.

\section{SUMMARY}

The importance of determining not only the nominal permeability of papers, but also the nature of the flow resistance was confirmed, for cigarette wrapper and for papers used in constructing ventilated filters. For perforated papers, for which the flow is not proportional to pressure drop, it was shown that logarithmic plotting and the use of the form $V=k(\Delta P)^{n}$ is satisfactory and convenient.

In applying this principle to ventilated filters it was found that limited, but significant, lateral flow occurs between the tipping and porous plug wrap papers, although the flow does not extend over the entire unglued area. With the use of small perforations and extremely porous plug wrap paper, the resistance of the plug wrap paper plays a very minor part in controlling dilution flow.

\section{ZUSAMMENFASSUNG}

Sowohl für Cigarettenpapiere als auch für Papiere, aus denen ventilierte Cigarettenfilter hergestellt werden, hat es sich als wichtig erwiesen, nicht nur den Nominalwert der Luftdurchlässigkeit zu bestimmen, sondern auch die Art des Strömungswiderstandes. Bei perforiertem Papier, bei dem der Volumenfluß dem Druckabfall nicht proportional ist, hat sich die logarithmische Auftragung und die Anwendung der Formel $\mathrm{V}=\mathrm{k}(\Delta \mathrm{P})^{\mathrm{n}}$ als geeignet und zufriedenstellend herausgestellt. 
Berüdksichtigt man dies bei ventilierten Filtern, so zeigt sich ein geringer, aber deutlich meßbarer Strom zwischen dem Mundstücksbelag und dem porösen Filterumhüllungspapier, wenngleich diese Beobachtung auch nicht über die gesamte ungeleimte Fläche gemadht wird. Hinsidhtlich der Kontrolle des Verdünnungsstromes spielt der Widerstand des Filterumhüllungspapiers bei kleinen Perforationslöchern und besonders porösem Filterumhüllungspapier eine untergeordnete Rolle.

\section{RESUME}

On a confirmé l'importance de la détermination non seulement de la perméabilité nominale des papiers, mais aussi de la nature de la résistance au flux d'air pour les papiers a cigarette et pour les papiers utilisés dans la confection des filtres ventiles. En ce qui concerne les papiers perforés, pour lesquels le flux n'est pas proportionnel a la résistance au tirage, on a montré qu'une représentation logarithmique et l'application de la formule $\mathrm{V}=\mathrm{k}(\Delta \mathrm{P})^{\mathrm{n}}$ sont satisfaisantes et adéquates.

En appliquant ce principe aux filtres ventiles, il a été constaté qu'un flux latéral, limité mais significatif, apparaît entre le papier de bout et l'enveloppe pour filtre poreuse bien que ce flux ne s'étende pas à toute la partie non collée. En utilisant de petites perforations et une enveloppe pour filtre extrêmement poreuse, la résistance de l'enveloppe pour filtre joue un rôle minime dans le contrôle de la dilution.

\section{REFERENCES}

1. Lipp, G.: Beitr. Tabakforsh. 3 (1966) 477.

2. Lipp, G., and H. van Nooy: Beitr. Tabakforsch. 1 (1962) 369.

3. Coresta Recommended Method No. 3: Determination of the air permeability of cigarette paper; Coresta Information Bulletin 1975-3/4, 38-41.

4. Kent, R. T.: Kent's mechanical engineers' handbook; Wiley, New York, 1946, I-11.

5. Mattina, C. F., and W. A. Selke: Recent advances in the chemical composition of tobacco and tobacco smoke; Proceedings of the American Chemical Society Symposium, 173rd Meeting, New Orleans, L.a., 1977, 545.

6. Jarman, R. T.: Paper presented at the Fourteenth Tobacco Chemists' Researdh Conference, WinstonSalem, N. C., U.S.A., October 1960.

7. Lorenz, H. W., and F. Seehofer: Beitr. Tabakforsch. 6 (1971) 1.

8. Mattina, C. F, and W. A. Selke: Op. cit. 546.

\section{Adknowledgement}

The authors wish to adknowledge the assistance given them by their colleague Hilary Walker.

Authors' address:

Researdh Department, Schweitzer Division, Kimberly-Clark Corporation, Lee, Massachusetts, 01238, U.S.A. 